\title{
Neural network model for forecasting the development of road transport enterprises in a non-stationarity economy
}

\author{
Svetlana Borodulina ${ }^{1, *}$ \\ ${ }^{1}$ Admiral Makarov State University of Maritime and Inland Shipping, Dvinskaya str. 5/7, St. \\ Petersburg, 198035, Russia
}

\begin{abstract}
The paper presents the results of the study of the influence of factors on the development indicators of road transport enterprises, describes the development indicators and their dynamics. On the basis of the theoretical foundations of non-stationarity, an interpretation of the concept of non-stationarity of the development of the economy and the industry market is proposed. On the basis of the crisis development scale developed by the author, the results of the cluster analysis of enterprises in the sample and the data of statistical processing of effective performance indicators, the forecast of the crisis development of road transport enterprises of Saint Petersburg in the transport services market of the region is made using neural network modeling. With the help of the constructed neural network model of the dependence of the degree of crisis on the most significant indicators, it is possible to predict the development of crisis situations, and this indicates the possibility of predicting the non-stationarity development of road transport enterprises and the economy as a whole.
\end{abstract}

\section{Introduction}

The development of relations between participants of the transport services market in the Russian Federation at the enterprise level is spontaneous, and the results of the influence of spontaneity and non-stationarity are largely determined by probabilistic factors $[1,2,3]$. Achieving flexibility in the management of road transport enterprises is possible on the basis of a timely forecast of the dynamics of their development, taking into account the nature and parameters of the development of the crisis in the conditions of non-stationarity. One of the functions of the management of road transport enterprises (RTE) in the conditions of nonstationarity is the function of forecasting and preventing the negative impact of crisis factors. The effect of external and internal factors of crisis on the activity of the road transport enterprises is manifested through the dynamics of indicators that comprehensively reflect the results of the operation of the enterprise in the market [1].

\footnotetext{
${ }^{*}$ Corresponding author: piter00000@mail.ru
} 


\section{Materials and Methods}

The use of neural network modeling in forecasting the development of transport enterprises seems to be most adequate in a group of enterprises that have the same reaction to the emerging non-stationarity in the economy. In this regard, in this study, the groups of road transport enterprises are identified by the method of cluster analysis (No 1, No 2, No 3), reflecting similar reactions to changes in factors and showing the same manifestations in the effective indicators. As the initial data for neural network modeling, we used the performed statistical processing of factors describing the adaptability of the road transport enterprises to crisis phenomena. The calculations were made using data on the annual values of 12 indicators for 25 automobile enterprises registered in Saint - Petersburg and the Leningrad Region. Using the factor analysis performed at the previous stage in the SPSS program, insignificant indicators were eliminated. As a result of data processing, independent variables were selected for further analysis and forecast: P1, P3, P6, P9, P10, P11, P12, reflecting the impact of crisis situations on the activities of road transport enterprises. Among them: current liquidity coefficient P1, autonomy coefficient P3, line output coefficient P6, traffic volume indices P9 and cargo turnover indices P10; chain revenue change index P11, chain cost change index P12. Their dynamic is shown in figure 1.

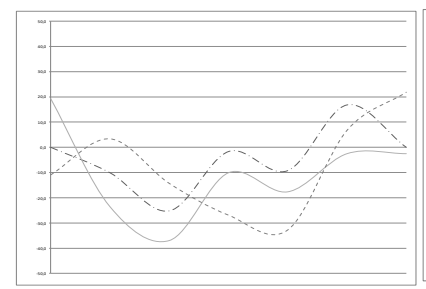

a) P1

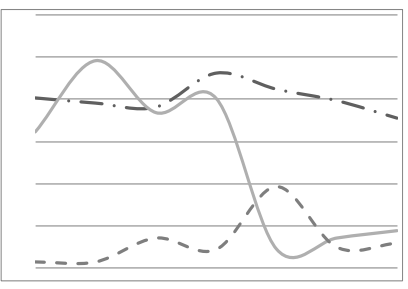

b) P3

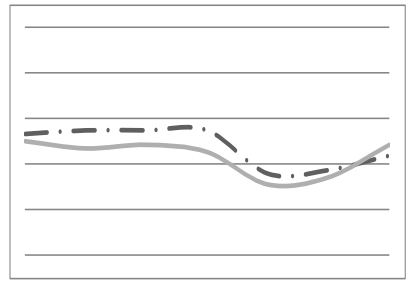

c) P6

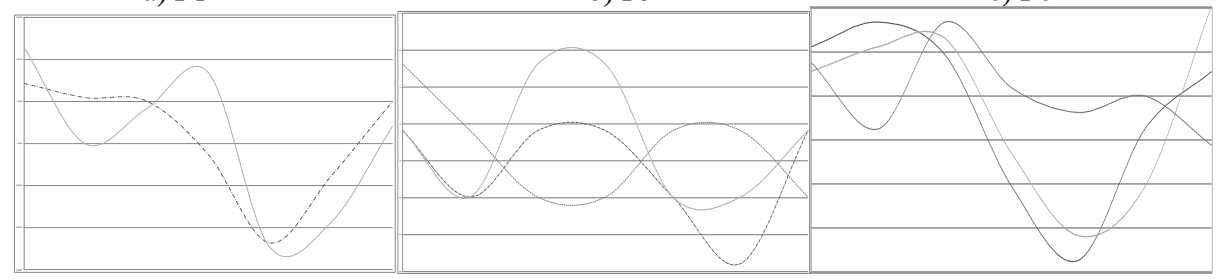

d) P9

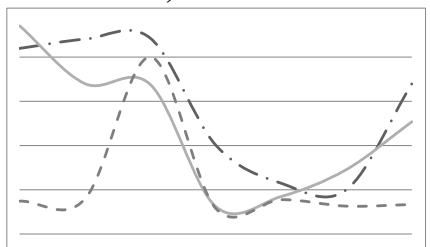

g) P12

e) P10

f) P11

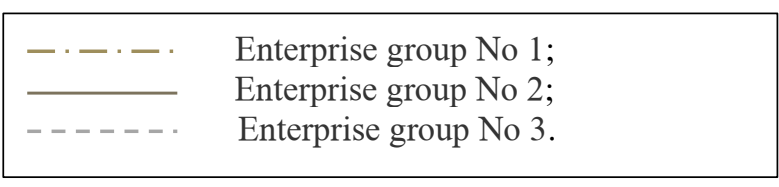

Fig. 1. The dynamic of the initial indicators used to predict the development of road transport enterprises.

The peculiarity of the enterprises operating in the transport services market today is the fact that their development and activity take place in conditions of instability, aggressive and dynamic external environment [2,3]. The non-stationarity of a system can manifest itself through its different reactions to the same perturbations affecting the system in different time periods $[2,4]$. One of the ways that systems maintain a state of stability is based on the Le Chatelier's principle according to which any external influence generates system responses that will be aimed at weakening the negative effect and maintaining stability. The 
characteristic of a steady or stable state of the system will be associated with the relative immutability of the output parameters of the system (road transport enterprises indicators).

Non-stationarity in this paper is the state of the road transport enterprises, which is expressed in the periodically recurring variability of the parameters of the model of their functioning with cyclically recurring crises. The non-stationarity of the market dynamics generates instability of the average performance of enterprises $[4,5,6,7]$. Instability in the market of transport services is manifested in the form of periodic deterioration of the enterprise's performance under the influence of factors. The management of transport enterprises should be carried out taking into account the specific speed of the road transport enterprises response to non-stationarity, which can be identified by neural network forecasting. The neural network provides a high speed of data processing, allows input with inaccurate and incomplete data, providing an approximate answer based on the principle of maximum or average similarity [8], which makes it possible to use it in studies based on incomplete data sets, as in the situation of studying the development of the crisis of road transport enterprises.

The advantage of the neural network is the ability to learn $[8,9,10]$. This software is increasingly used in Russia, however, the results of the research of the road transport enterprises in Saint - Petersburg suggest that this technology is not used in their practical activities. The use of neural network technologies as tools is promising in solving many poorly formalized problems, in particular, in assessing the crisis $[11,12,13,14,15]$, and therefore in analyzing the development of road transport enterprises in non-stationarity conditions. The accuracy of the forecast, according to experts, achieved when using neural network technologies in solving real problems, has already exceeded $95 \%$. All this shows in favor of the practical significance of the model being constructed for predicting crises in the enterprise's activities.

\section{Results and discussion}

The paper sets the task of predicting the state of the above-studied road transport enterprises in non-stationarity conditions of development. The monitoring is based on the Z-crisis rating obtained in the course of an expert survey (Table 1).

Table 1. Scale of expert assessments of the crisis of the functioning of road transport enterprises for use in the forecast.

\begin{tabular}{|c|c|c|c|l|}
\hline \multicolumn{2}{|c|}{$\begin{array}{c}\text { Degree intervals of } \\
\text { Z-crisis situations }\end{array}$} & \multicolumn{1}{c|}{$\begin{array}{c}\text { Characteristics } \\
\text { of the degree of crisis }\end{array}$} & \multicolumn{1}{c|}{ Notes } \\
\hline-1.0 & & 0 & $\begin{array}{c}\text { no crisis, } \\
\text { minor difficulties }\end{array}$ & $\begin{array}{l}\text { With an increase in non-essential } \\
\text { difficulties, the Z value approaches 0 }\end{array}$ \\
\cline { 4 - 5 } & \multirow{2}{*}{$<Z \leq$} & 0.2 & $\begin{array}{c}\text { pre-crisis state or stage of } \\
\text { mild crisis }\end{array}$ & $\begin{array}{l}\text { (According to the results of the study, } \\
\text { up to 20\% of the crisis) }\end{array}$ \\
\cline { 3 - 5 } 0.2 & 0.5 & $\begin{array}{c}\text { medium degree of } \\
\text { crisis situations }\end{array}$ & $\begin{array}{l}\text { Crisis phenomena can be eliminated by } \\
\text { anti-crisis measures }\end{array}$ \\
\cline { 3 - 5 } 0.5 & 1.0 & $\begin{array}{c}\text { deep, } \\
\text { protracted crisis, } \\
\text { financial disaster }\end{array}$ & $\begin{array}{l}\text { Deep or protracted crisis, starting from } \\
50 \% \text { increases to } 100 \% \\
\text { (the situation of financial disaster) }\end{array}$ \\
\hline
\end{tabular}

With the help of the SPSS program and its block - the neural network model - the result of clustering is obtained, which is a grouping of the city's road transport enterprises by the magnitude of the crisis indicator.

The dendrogram for the selected indicators allowed identifying similar groups of enterprises in terms of the strength of their response and the variability of their indicators to the impact of crisis factors. The formed cluster matrix allowed distinguishing 3 clusters of 
the studied enterprises according to the similarity of reactions. Thus, cluster No 1 enterprises are represented by small businesses, they actively respond to the first "seeds" of the crisis, and demonstrate the rapid manifestation of the symptoms of the crisis. Cluster No 2 includes small and medium-sized enterprises, they demonstrate an average reaction rate to crisis factors, which is explained by the accumulated safety margin. The third cluster is represented by stable enterprises with a good margin of stability and a slow response to crises.

The selected clusters of enterprises by 7 indicators and values of the Z-degree of crisis became the basis for the development of a neural network model for predicting the development of the road transport enterprises and crises in its activities. The results of constructing a neural network model in the STATISTICA program based on the average values of cluster No 1 are given in Table 2. The specified parameters are: input variables: P1, P3, P6, P9, P10, P12; output variable: Z; task type: time series.

Table 2. Results of constructing models for cluster No 1 of enterprises.

\begin{tabular}{|l|l|c|c|c|c|c|c|}
\hline \multicolumn{7}{|c|}{ Detailed model results (cluster 1 averages) } \\
\hline No & architecture & $\begin{array}{c}\text { learning } \\
\text { performance }\end{array}$ & $\begin{array}{c}\text { control } \\
\text { performance }\end{array}$ & $\begin{array}{c}\text { test } \\
\text { performance }\end{array}$ & $\begin{array}{c}\text { training } \\
\text { error }\end{array}$ & $\begin{array}{c}\text { control } \\
\text { error }\end{array}$ & $\begin{array}{c}\text { test } \\
\text { error }\end{array}$ \\
\hline 1 & $\begin{array}{l}\text { RBF s4 1:4- } \\
3-1: 1\end{array}$ & 0.503315 & 0.482206 & 1.550650 & 2.031391 & 2.693950 & 1.486613 \\
\hline 2 & $\begin{array}{l}\text { Linear s3 } \\
5: 15-1: 1\end{array}$ & 0.000000 & 0.377704 & 7.458959 & 0.000000 & 0.231484 & 0.456944 \\
\hline 3 & $\begin{array}{l}\text { Multi-layer } \\
\text { perceptron } \\
\text { (MP) s5 } \\
6.30-1-1: 1\end{array}$ & 0.255343 & 0.258369 & 1.846702 & 0.070282 & 0.089976 & 0.469199 \\
\hline 4 & $\begin{array}{l}\text { Linear s3 } \\
6: 18-1: 1\end{array}$ & 0.000000 & 0.105104 & 5.610083 & 0.000000 & 0.076092 & 0.269744 \\
\hline 5 & $\begin{array}{l}\text { Multi-layer } \\
\text { perceptron } \\
\text { s5 } \\
7: 35-7-1: 1\end{array}$ & 0.490753 & 0.142793 & 5.690241 & 0.165156 & 0.053377 & 0.209572 \\
\hline
\end{tabular}

The best network found was model No 5 -multi-layer perceptron (architecture MP s57: 35-7-1:1), which has a fairly good performance (regression ratio 0.142793 , error 0.053377 ). The network architecture, i.e. the sequence of layers of neurons and their connections, is shown in figure 2 .

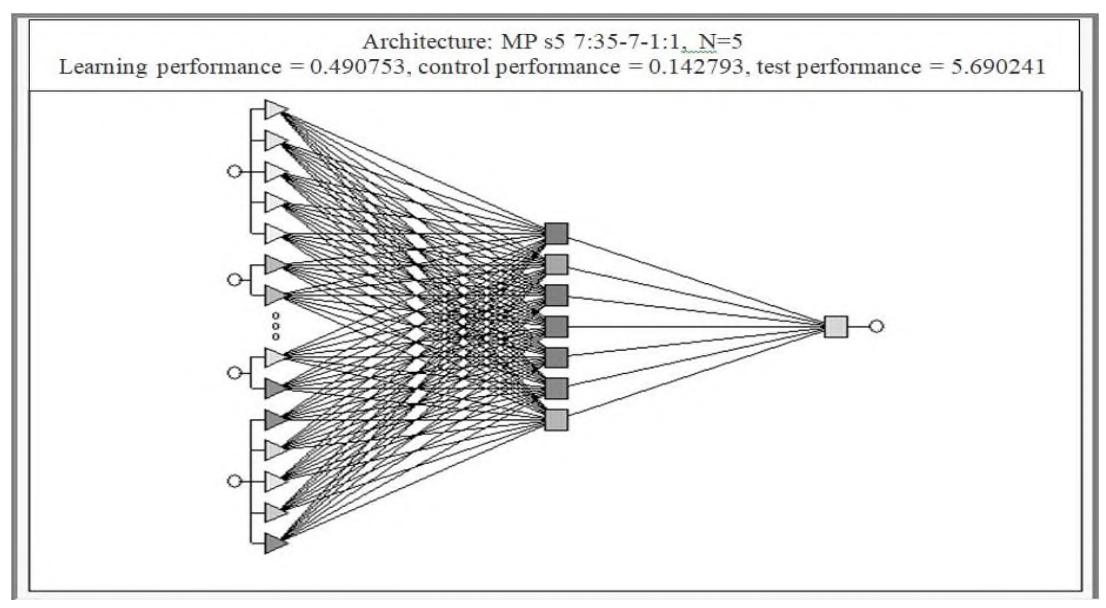

Fig. 2. Characteristics of the neural network architecture (MP S5) for enterprises of the cluster No 1. 
This neural network allowed obtaining a forecast of the values of the $Z$ index, which characterizes the crisis of the road transport enterprises in the short term. The graph (figure 3 ) of the observed (actual business statistics data) Z-values and the predicted (forecast) data from the MP 5 model clearly proves that if the $Z$ values are in the middle of the interval (approximately from -0.3 to 0.6 ), the most of the values are located near the bisector of the coordinate angle. Therefore, within these limits, the observed $Z$ and predicted values are close to each other and indicate the presence of crises of varying severity from minor difficulties to a deep, protracted crisis in the forecast. This conclusion is confirmed by the analysis of the distribution of the squares of the residuals, where, with the exception of one, the residuals are concentrated near zero (from 0 to 0.06 ). Let's compare the relative position of the observed average $Z$ values for the enterprises of the $1^{\text {st }}$ cluster and those values that are obtained as a result of the operation of MP 5 model (figure 4).
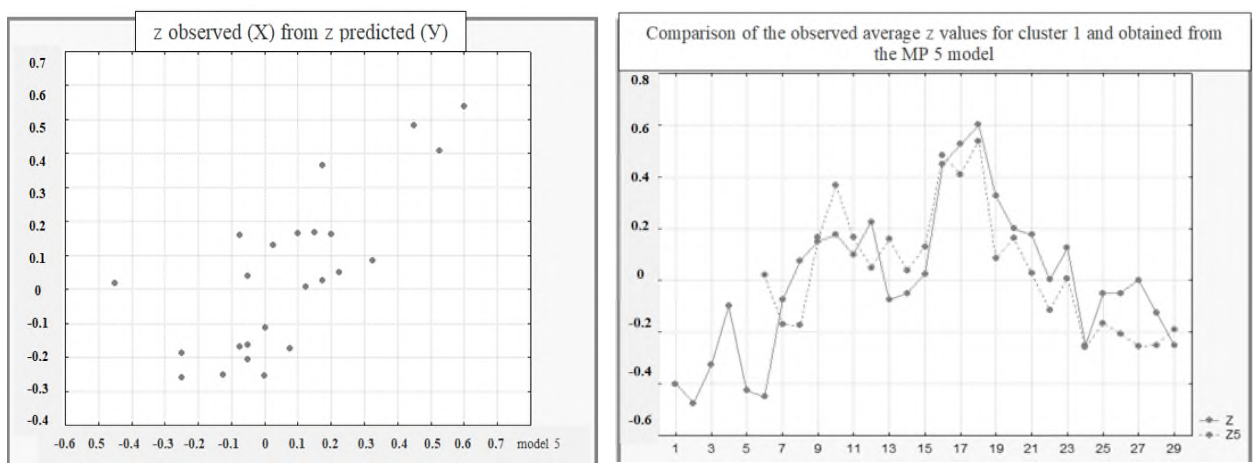

Fig. 3. Statistical data and forecast values of the Fig. 4. Comparison of statistical data on the Z-crisis Z-crisis of road transport enterprises (cluster 1) of the road transport enterprises (1 cluster) and in the MP5 model. obtained from the MP5 model.

Obviously, the two lines are close to each other, which confirms that this model really reflects the degree of crisis of transport enterprises (Z5), since the deviations from the actual values of crisis $(Z)$ are small. This suggests that further forecasts of the $Z$-degree indicator of the crisis will have a high degree of accuracy. The data of $Z$ forecasts for cluster enterprises No 1 based on the MP5 neural network model are presented in figure 5. Similar forecast calculations can also be performed for enterprises of other clusters.

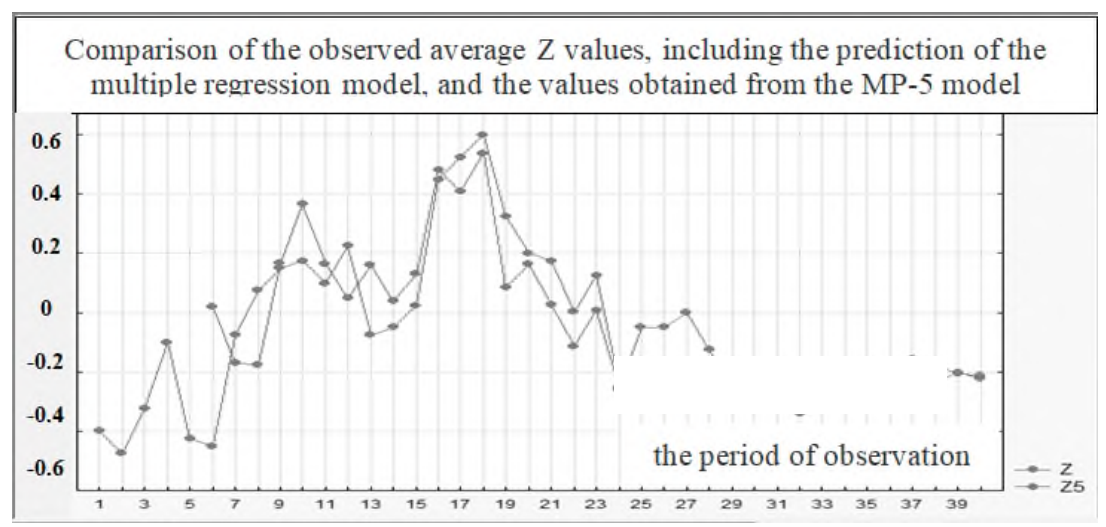

Fig. 5. Forecast of the Z-degree of crisis of the road transport enterprises according to the MP5 neural network model (cluster No 1). 
Thus, neural networks with a good statistical base for solving problems of predicting the crisis and danger to the functioning of road transport enterprises can become an effective management tool in the conditions of non-stationarity development.

\section{Conclusions}

The advantages of neural networks as a tool for modeling complex processes for management, such as crises in the activities of the road transport enterprises, or forecasting crises in the conditions of non-stationarity economic development, are obvious. The neural network model developed and tested for predicting the development of crises confirmed the hypothesis about the possibility of predicting and early diagnosing crises in the activity of the road transport enterprises in the conditions of non-stationarity. In this case, the model becomes one of the tools for implementing flexible management at transport enterprises, and its use in combination with optimization and decision-making methods will allow obtaining synthesized methods and techniques for maintaining the stability of the enterprise in the conditions of non-stationarity economic development.

Constructed neural network model of the dependence of the $Z$-crisis rate on the most significant indicators of road transport enterprises, made it possible to forecast the development of crisis situations, which indicates the possibility of forecasting the nonstationarity of the road transport enterprises and the economy as a whole, and confirms the significance of the results obtained.

\section{References}

1. S. Borodulina, T. Pantina, Model of sustainable economic development in the context of inland water transport management. Springer, Cham, 806-819 (2020) https://doi.org/10.1007/978-3-030-57450-5_68

2. S. Glaz'yev, Nanotechnology is a key factor in the new technological order (2019) https://doi.org/10.26794/2587-5671-2015-0-1-64-68

3. Y.I. Rastova, M.A. Rastov, Strategic Management of a Modern Organization 8(3), 20 31 (2018) https://doi.org/10.26794/2404-022X-2018-8-3-20-31

4. G.I. Parisi, R. Kemker, J. Part, C. Kanan, S. Wermter, Neural Networks 113, 54-71 (2019) https://doi.org/10.1016/j.neunet.2019.01.012

5. Fekri Ali Shawtari, Milad Salem, Hafezali Iqbal-Hussain, Omar Alaeddin, Abdullah Omer, Journal of Economics, Finance and Administrative Science 21(41), 81-88 (2016) doi:10.1016/j.jefas.2016.06.004

6. Amin Hedayati Moghaddam, Journal of Economics and Finance 21, 89-93 (2016) doi:10.1016/j.jefas.2016.07.002PDF 4 КБ

7. A.-S. Chen, M. Leung, H. Daouk, Computers \& Operations Research 30(6), 901-923 (2003) doi:10.1016/S0305-0548(02)00037-0

8. J. Schmidhuber, Deep learning in neural networks: An overview Neural Networks 61, 85-117 (2015) https://doi.org/10.1016/j.neunet.2014.09.003

9. J.L. Lobo, J. Del Ser, A. Bifet, N. Kasabov, Spiking Neural Networks and online learning: An overview and perspectives 121, 88-100 (2020) https://doi.org/10.1016/j.neunet.2019.09.004

10. J. Przemyslaw, K. Jan, T. Katarzyna, Intelligent Decision Technologies Springer, Cham SIST 57, 127-138 (2016) doi: 10.1007/978-3-319-39627-9_12 
11. E. Alfaro, N. García, Decision Support Systems 45, 110-122 (2008) doi: 10.1016 / j.dss.2007.12.002

12. S. Amanati, Research Journal of Applied Sciences, Engineering and Technology Corpus 17052181 doi:10.19026/RJASET.7.915

13. J. Baek, S. Cho, Proceedings IEEE 2003, 25-29 (2003) doi:10.1016/j.jefas.2016.07.002

14. P. Hájek, Decision Support Systems 51, 108-118 (2011) doi:10.1016/j.dss.2010.11.033

15. K. Lee, Expert Systems with Applications 29, 1-16 (2005) doi: 10.1109 / ECACE.2019.8679360 